\title{
New discoveries at the interface of boron and carbon chemistries*
}

\author{
M. Frederick Hawthorne \\ Department of Chemistry and Biochemistry, University of California, Los Angeles, \\ CA 90024, USA
}

\begin{abstract}
The continued growth of polyhedral borane chemistry is illustrated by the successful synthesis of $\left[\text { closo }-\mathrm{B}_{12}(\mathrm{OH})_{12}\right]^{2-}$ by the $\mathrm{H}_{2} \mathrm{O}_{2}$ oxidation of $\left[\text { closo }-\mathrm{B}_{12} \mathrm{H}_{12}\right]^{2-}$. The hydroxylated species reacts with common organic reagents to produce 12 -fold degenerately substituted carboxylate esters, ethers, and carbamate esters. The ether derivatives undergo facile and reversible redox reactions in which the $\mathrm{B}_{12}$ scaffold serves as a one- or two-electron donor giving stable oxidation states described by [closo- or hypercloso- $\left.\mathrm{B}_{12}(\mathrm{OR})_{12}\right]^{n}$ with $n=-2,-1$, and 0 . The loss of polyhedral electrons is compensated by back-bonding from the attached ether oxygen substituents. Structural comparisons are presented along with representative reaction chemistry. Derivatives that bear functional groups on the termini of the 12-fold set of substituents provide a vast array of potential applications. To distinguish these new polyfunctional icosahedral species from dendrimers, they have been designated as closomers.
\end{abstract}

\section{INTRODUCTION}

The future of polyhedral boranes is dependent upon the continued fusion of their remarkable chemistry with that of carbon. With time, two types of organoborane chemistry have emerged; organoborane chemistry in which simple compounds such as trialkyboranes have augmented and enhanced organic chemistry [1] and a cleanly separated organoborane chemistry in which organic and organometallic chemistries have fused with polyhedral boranes to produce a seamless "organoborane chemistry of the second kind" $[2,3]$. This chemistry is richly endowed with opportunities for further discovery and unique technological applications unavailable elsewhere in the periodic table. The recently described discovery $[4,5]$ of $\left[\text { closo- } \mathrm{B}_{12}(\mathrm{OH})_{12}\right]^{2-}, \mathbf{1}$, provides such an advance in polyhedral borane chemistry.

\section{POLYFUNCTIONALIZED BORANE CLUSTERS: CLOSOMERS}

\section{Polyhydroxylation of $\mathrm{BH}$ vertices in icosahedral structures}

Oxidation of [closo- $\left.\mathrm{B}_{12} \mathrm{H}_{12}\right]^{2-}$ and other isoelectronic closo species [4], such as [ closo- $\left.\mathrm{CB}_{11} \mathrm{H}_{12}\right]^{-}$and partially water-soluble derivatives of closo-1,12- $\mathrm{C}_{2} \mathrm{~B}_{10} \mathrm{H}_{12}$, with hydrogen peroxide leads to the total replacement of all BH vertices by BOH. In this way, $\left[\text { closo- } \mathrm{B}_{12}(\mathrm{OH})_{12}\right]^{2-}, \mathbf{1} ;\left[\text { closo- } 1-\mathrm{H}-1-\mathrm{CB}_{11}(\mathrm{OH})_{11}\right]^{-}$, 2; and [closo-1,12-( $\mathrm{H})_{2}-1,12-\mathrm{C}_{2} \mathrm{~B}_{10}(\mathrm{OH})_{10}, 3$, became available for further exploration. These hydroxylated derivatives are the only known polyhedral borane species of any type which have all boron vertices substituted with functional groups. Scheme 1 summarizes these reactions, which were carried out with $30 \% \mathrm{H}_{2} \mathrm{O}_{2}$ at elevated temperatures. The course of the oxidation of closo-1,12-( $\left(\mathrm{HOCH}_{2}\right)_{2}-1,12-$

* Lecture presented at the $\mathrm{XI}^{\text {th }}$ International Meeting on Boron Chemistry (IMEBORON XI), Moscow, Russia, 28 July-2 August 2002. Other presentations are published in this issue, pp. 1157-1355. 
$\mathrm{C}_{2} \mathrm{~B}_{10} \mathrm{H}_{10}$ to closo-1,12-( $\left.\mathrm{H}\right)_{2}-1,12-\mathrm{C}_{2} \mathrm{~B}_{10}(\mathrm{OH})_{10}, 3$, apparently involves the oxidation of the $-\mathrm{CH}_{2} \mathrm{OH}$ substituents to $-\mathrm{COOH}$ followed by decarboxylation. The structures of $\mathbf{1}, \mathbf{2}$, and $\mathbf{3}$ were determined by $\mathrm{X}$-ray diffraction studies, and the unusual water solubilities of the alkali metal, $\mathrm{NH}_{4}{ }^{+}$and $\mathrm{H}_{3} \mathrm{O}^{+}$salts of $\mathbf{1}$ have been reported [5] along with their structures. Such simple salts of $\mathbf{1}$ are aggregated by coordination of the many oxygen atoms of the $-\mathrm{OH}$ substituents with the alkali metal cations and by similar hydrogen-bonding interactions with $\mathrm{NH}_{4}^{+}$and $\mathrm{H}_{3} \mathrm{O}^{+}$cations. The cesium cation provides the most water-soluble salt of $\mathbf{1}$ known, to date. The $\mathbf{1}$ dianion is easily converted to quaternary ammonium and phosphonium salts which display solubility in organic solvents. Species 1, 2, and $\mathbf{3}$ are stable and serve as starting materials in further reactions such as those described below.

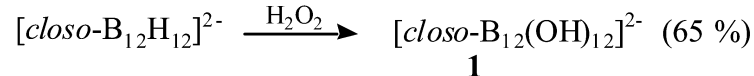

$$
\begin{aligned}
& \text { [closo- } \left.\left.\mathrm{CB}_{11} \mathrm{H}_{12}\right]^{-} \stackrel{\mathrm{H}_{2} \mathrm{O}_{2}}{\longrightarrow} \text { [closo-1-H-1- } \mathrm{CB}_{11}(\mathrm{OH})_{11}\right]^{-} \quad(15 \%) \\
& 2 \\
& \text { closo-1,12-( } \left.\left(\mathrm{HOCH}_{2}\right)_{2}-1,12-\mathrm{C}_{2} \mathrm{~B}_{10} \mathrm{H}_{10} \stackrel{\mathrm{H}_{2} \mathrm{O}_{2}}{\longrightarrow} \text { closo-1,12-(H) }\right)_{2}-1,12-\mathrm{C}_{2} \mathrm{~B}_{10}(\mathrm{OH})_{10}(80 \%)
\end{aligned}
$$

Scheme 1 Hydroxylation of icosahedral borane derivatives with $\mathrm{H}_{2} \mathrm{O}_{2}$.

Reactions of $\mathbf{1}$ designed to explore the reactivity of the BOH hydroxyl groups revealed that their response to acylation, [6] ether formation [7], and reaction with isocyanates to form carbamate esters are similar to that of simple alcohols. To achieve 12-fold functionalization, long reaction times (days) at elevated temperatures were often required $\left(>100^{\circ} \mathrm{C}\right)$. The resulting products, discussed below, have unique structures and functions not found elsewhere in chemistry. Although at first sight these unusual dianions resemble dendrimers, they differ by having a 12-fold functional core (1). This level of functionality is obtained without branching a smaller molecule. However, each of the 12 anchoring $\mathrm{BOH}$ functions could, in principle, support a dendritic chain having several generations of repeating units. In order to focus upon their unique structures, we have named the derivatives of $\mathbf{1}$ (and similar species) "closomers", a name which emphasizes the nature of their molecular scaffolding [6,7].

\section{Carboxylate ester closomers}

The reactions of $\mathbf{1}$ with reagents commonly employed for the esterification of primary and secondary alcohols have been investigated. This exploratory chemistry employed carboxylic acid anhydrides, acyl and aroyl chlorides, and the activation of carboxylic acids with $N, N^{\prime}$-carbonyldiimidazole. Representative carboxylate ester closomers, [closo- $\left.\mathrm{B}_{12}(\mathrm{OCOR})_{12}\right]^{2-}$, include those with $\mathrm{R}=-\mathrm{CH}_{3},-\mathrm{CH}_{2} \mathrm{CH}_{3}$, $-\mathrm{CH}_{2} \mathrm{CH}_{2} \mathrm{OCH}_{3},-\left(\mathrm{CH}_{2}\right)_{4} \mathrm{COOCH}_{3},-\left(\mathrm{CH}_{2}\right)_{5} \mathrm{NHCOCF}_{3},-4-\mathrm{C}_{6} \mathrm{H}_{4} \mathrm{CN},-4-\mathrm{C}_{6} \mathrm{H}_{4} \mathrm{CH}_{2} \mathrm{NHCOCF}_{3}$, and $-4-\mathrm{C}_{6} \mathrm{H}_{4} \mathrm{COCl}$. Figure 1 presents an ortep structure of the dodecaacetate, and Fig. 2 contains a spacefilling representation of the dodecabenzoate based upon single-crystal X-ray diffraction data. The high sphericity of the icosahedral core illustrated in both of these representations provides wide separation of substituent termini from each other at moderate distances from the icosahedral surface. This structural feature allows the attachment of additional substituents to the closomer termini as shown in Scheme 2 where $\mathrm{R}=-1,4-\mathrm{C}_{6} \mathrm{H}_{4}-$ or $-\left(\mathrm{CH}_{2}\right)_{6}$. Extension of closomer structures may provide useful applications in biomedicine, biotechnology, pharmaceutical research, and materials science. The hydrolytic stability of closomer carboxylate esters has been examined in aqueous solution with the dodecaacetate. 


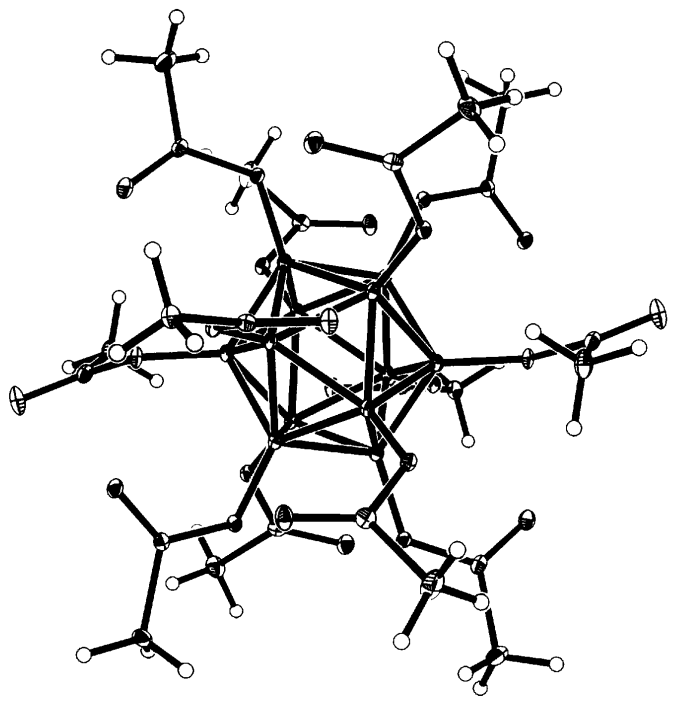

Fig. 1 Ortep representation of $\left[\text { closo- } \mathrm{B}_{12}\left(\mathrm{OCOCH}_{3}\right)_{12}\right]^{2-}$.

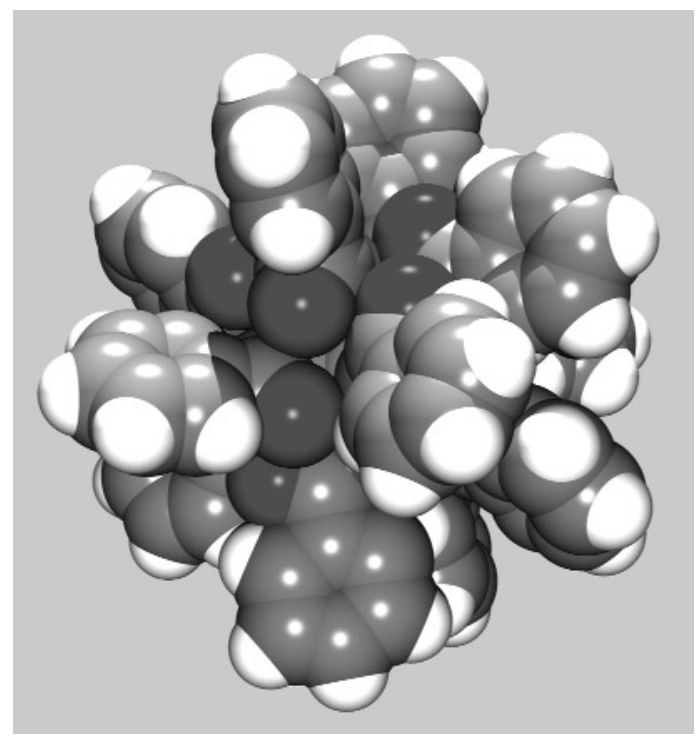

Fig. 2 Space-filling representation of $\left[\text { closo }-\mathrm{B}_{12}\left(\mathrm{OCOC}_{6} \mathrm{H}_{5}\right)_{12}\right]^{2-}$.

Hydrolysis becomes apparent at $\mathrm{pH} 3$ and increases in rate at lower $\mathrm{pH}\left(25^{\circ} \mathrm{C}\right)$; rapid reaction was observed above $\mathrm{pH} 12$. The dodecaacetate was stable in fresh calf serum containing a variety of enzymes including esterases.

$\left[\text { closo-B }{ }_{12}(\mathrm{OH})_{12}\right]^{2-} \stackrel{\mathrm{R}(\mathrm{COCl})_{2}}{\longrightarrow}\left[\text { closo- } \mathrm{B}_{12}(\mathrm{OCORCOCl})_{12}\right]^{2-} \stackrel{\mathrm{R}^{\prime} \mathrm{NH}_{2}}{\longrightarrow}\left[\text { closo-B }{ }_{12}(\mathrm{OCORCONHR})_{12}\right]^{2-}$

Scheme 2 Synthesis of an ester 12(12)-closomer with extended functionality.

(C) 2003 IUPAC, Pure and Applied Chemistry 75, 1157-1164 


\section{Alkyl ether closomers and their novel redox chemistry}

Closomers containing ether linkages with alkyl and aralkyl groups are readily formed by the reaction of $\mathbf{1}$ with an appropriate halide derivative in the presence of a sterically hindered base such as a tertiary amine. The resulting dodecaether derivative having a -2 charge is easily oxidized in two sequential and reversible one-electron transfer reactions as shown in Scheme 3 where $\mathrm{R}=$ alkyl or aralkyl.

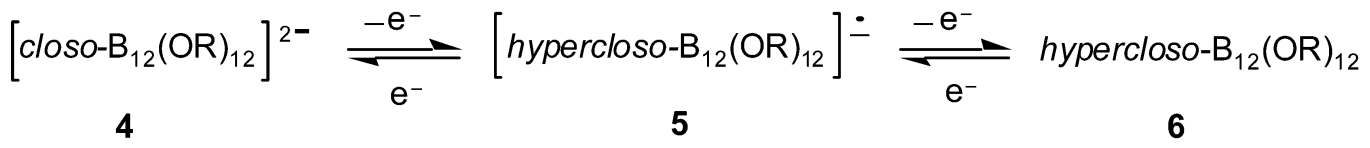

Scheme 3 Representative sequential oxidation of ether 12(12)-closomer.

The species 4, 5, and $\mathbf{6}$ contain 26, 25, and 24 cage-bonding electrons, respectively. Species 4 is colorless, paramagnetic $\mathbf{5}$ is reddish-purple, and yellow $\mathbf{6}$ is diamagnetic. Redox reactions which interconvert 4,5 , and $\mathbf{6}$ are conveniently conducted with $\mathrm{Fe}^{3+}$ and $\mathrm{BH}_{4}^{-}$as oxidant and reductant, respectively. X-ray diffraction studies using the dodecabenzyl ether system proved that $\mathbf{4}$ and $\mathbf{5}$ were isostructural within experimental error although 5 in $\mathrm{I}_{\mathrm{h}}$ symmetry has a degenerate HOMO array. The $\mathrm{D}_{3 \mathrm{~d}}$ structure of $\mathbf{6}$ is the result of Jahn-Teller distortion from $\mathrm{I}_{\mathrm{h}}$ symmetry. A space-filling structure of $\mathbf{4}(\mathrm{R}$ $=$ benzyl) and an ortep structure of $\mathbf{5}\left(\mathrm{R}=\right.$ benzyl) are presented in Figure 3 . The $\mathrm{D}_{3 \mathrm{~d}}$ cage structure of $6(\mathrm{R}=$ benzyl) is presented in Fig. 4 along with representative B-B and B-O bond lengths observed in both 4 and 6 . The six B-B distances denoted in the structure of 6 are long, compared to similar distances in $\mathbf{4}$, while B-O distances observed at these same B-atoms are shortened relative to those in $\mathbf{4}$. This shortening is due to backbonding of nonbonding oxygen electrons into the electron-deficient $D_{3 d}$ cage. Thus, the borane cages of $\mathbf{4 , 5}$, and $\mathbf{6}$ have the properties of a metal center characterized by redox reactions and the stabilization of electron-deficient oxidation states by ligand (ethereal oxygen) backbonding.

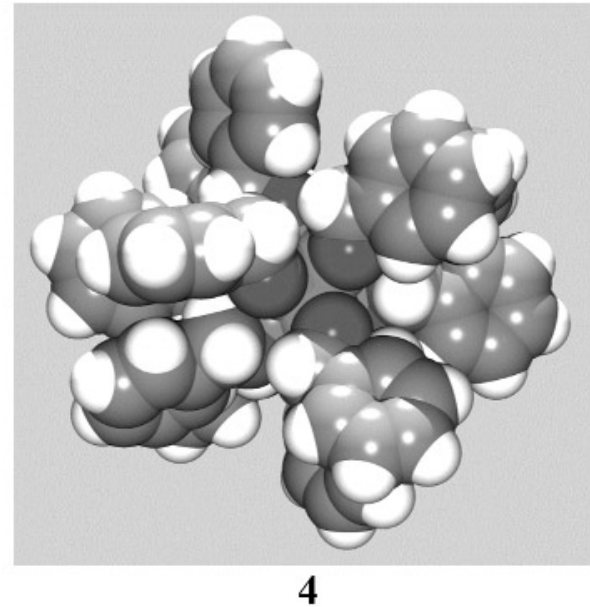

4

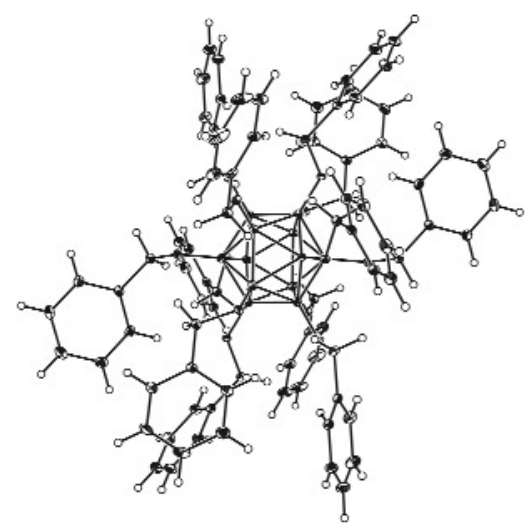

5

Fig. 3 Space-filling structure of $\left[\text { closo- } \mathrm{B}_{12}\left(\mathrm{OCH}_{2} \mathrm{C}_{6} \mathrm{H}_{5}\right)_{12}\right]^{2-}$ and ortep representation. 


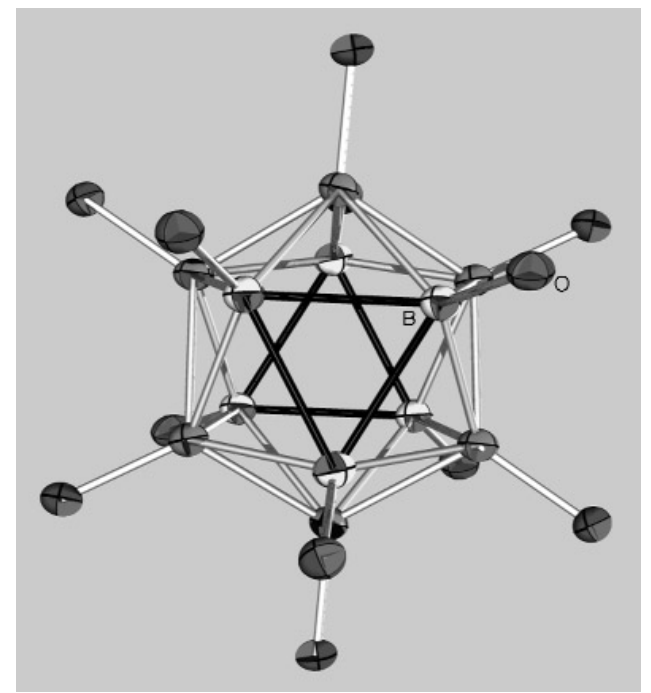

Fig. 4 Structure of the $\mathrm{D}_{3 \mathrm{~d}}$ closomer core of hypercloso- $\mathrm{B}_{12}\left(\mathrm{OCH}_{2} \mathrm{C}_{6} \mathrm{H}_{5}\right)_{12}$. The two triangles (dark) denote long [191.8 pm vs. $178.1-182.4 \mathrm{pm}$ in $4(\mathrm{R}=$ benzyl)] $\mathrm{B}-\mathrm{B}$ interactions and reduced electron density while the $\mathrm{B}-\mathrm{O}$ interactions at these same six B-atoms are shortened [136.9 pm vs. 143.4-145.1 pm in 4 ( $\mathrm{R}=$ benzyl)] by backbonding from oxygen.

The redox reactions presented in Scheme 3 have been studied using cyclic voltammetry with a variety of substituents. Table 1 presents representative data for the $\mathbf{4 / 5}$ and $\mathbf{5 / 6}$ interconversions.

Table 1 Redox data for representative closomer ethers. ${ }^{\mathrm{a}}$

\begin{tabular}{lcc}
\hline Closomer substituent, $\mathrm{R}$ & $E_{1 / 2}(\mathbf{4 / 5}), \mathrm{V}$ & $E_{1 / 2}(\mathbf{5 / 6}), \mathrm{V}$ \\
\hline$-\mathrm{CH}_{2} \mathrm{C}_{6} \mathrm{H}_{5}$ & -0.15 & 0.47 \\
$-\mathrm{CH}_{3}$ & -0.67 & 0.01 \\
$-\left(\mathrm{CH}_{2}\right)_{3} \mathrm{CH}_{3}$ & -0.69 & 0.04 \\
$-\left(\mathrm{CH}_{2}\right)_{5} \mathrm{CH}_{3}$ & -0.70 & 0.00 \\
\hline
\end{tabular}

${ }^{a}$ Potentials determined vs. $\mathrm{Ag} / \mathrm{AgCl}$ using tetrahydrofuran solvent and $n-\mathrm{Bu}_{4} \mathrm{~N}^{+} \mathrm{ClO}_{4}^{-}$supporting electrolyte.

Data from Table 1 indicate that the $\mathbf{4 / 5}$ interconversion occurs with $E_{1 / 2}$ potentials of -0.15 to $-0.70 \mathrm{~V}$ with all substituents. However, the $\mathbf{5 / 6}$ interconversions have $E_{1 / 2}$ potentials of 0.47 with the closomer having $\pi$-electrons in the vicinity of the closomer core and $E_{1 / 2}$ potentials of 0.00 to $0.04 \mathrm{~V}$ for closomers having substituents with no $\pi$-electrons. Thus, the vivid role of proximate $\pi$-electrons in the $\mathbf{5 / 6}$ redox reactions cannot be explained at this time.

The redox reactions linking species $\mathbf{4}, \mathbf{5}$, and $\mathbf{6}$ is without precedent in the chemistry of polyhedral boranes. Backbonding of the available oxygen nonbonding electron pairs provides stabilization of 5 and 6. Stabilization of this sort is not apparent in the carboxylate ester closomers due to delocalization of the nonbonding oxygen electrons into the adjoining carbonyl group.

Computational analyses of $\mathbf{4 , 5}$, and $\mathbf{6}$ and related closomers have been reported by McKee [8] and the $\mathrm{D}_{3 \mathrm{~d}}$ structure of $\mathbf{6}$ accommodated. 


\section{Carbamate ester closomers}

The slow reaction of $\mathbf{1}$ with phenyl isocyanate produces the expected dodecacarbamate ester, $\mathbf{7}$, in good yield. Irreversible one-electron oxidation of $\mathbf{7}$ appears to form the corresponding anion radical, $\mathbf{8}$ at $0.80 \mathrm{~V}$ (vs. $\mathrm{Ag} / \mathrm{AgCl}$ ). Scheme 4 presents these reactions.

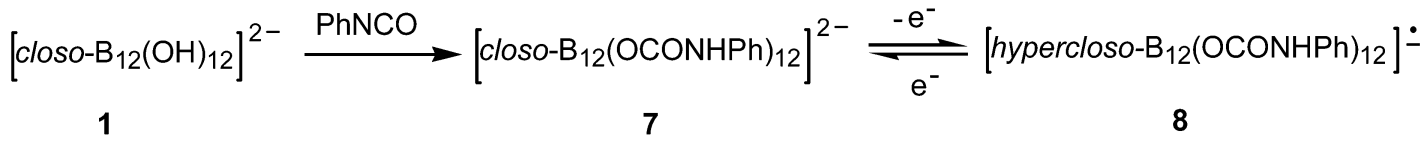

1

8

Scheme 4 Representative carbamate ester 12(12)-closomer and redox reaction.

The apparent oxidation of $\mathbf{7}$ to $\mathbf{8}$ must result from the fact that the nonbonded electron pairs present on the nitrogen atoms of $\mathbf{8}$ largely satisfy the electron-deficient carbonyl groups while the cagebonded oxygen atoms supply sufficient nonbonded electron density to stabilize the electron-deficient closomer cage in $\mathbf{8}$. Figure 5 illustrates the ortep structure of $\mathbf{7}$.

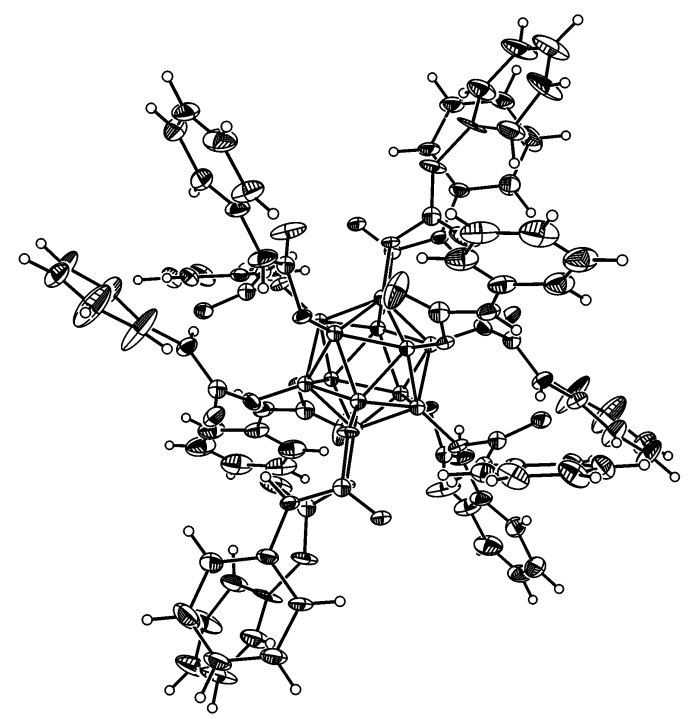

Fig. 5 Ortep representation of $\left[\text { closo- } \mathrm{B}_{12}\left(\mathrm{OCONHC}_{6} \mathrm{H}_{5}\right)_{12}\right]^{2-}$.

\section{EXTENSIONS OF CLOSOMER CHEMISTRY}

Polyhydroxylated boranes and carboranes represent new structural motifs for further exploratory chemistry. A recent report [9] describes carboxylate ester closomers based upon 1, while another study [10] describes novel carborane chemistry based upon closo-1,12-(H) $)_{2}-1,12-\mathrm{C}_{2} \mathrm{~B}_{10}(\mathrm{OH})_{10}, \mathbf{9}$.

\section{Molecular nanoparticle for boron neutron capture therapy}

Current interest in 30-150 nm-diameter unilamellar liposomes [11] as delivery systems for ${ }^{10} \mathrm{~B}$-enriched target molecules in boron neutron capture therapy suggests that boron-rich molecular nanoparticles, an order of magnitude smaller than liposomes, may also be worthy of investigation. Species of this sort are easily derived from closomers and have up to 12 polyhedral borane moieties attached to 1 . Such species have been synthesized [9] as described in Scheme 5. A computer simulation of the structure of 


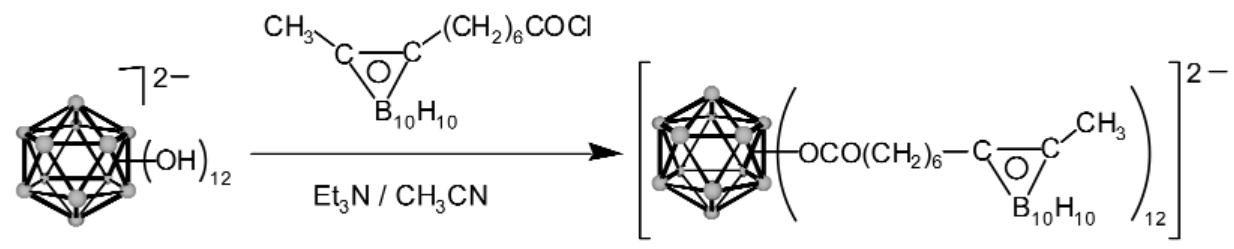

10
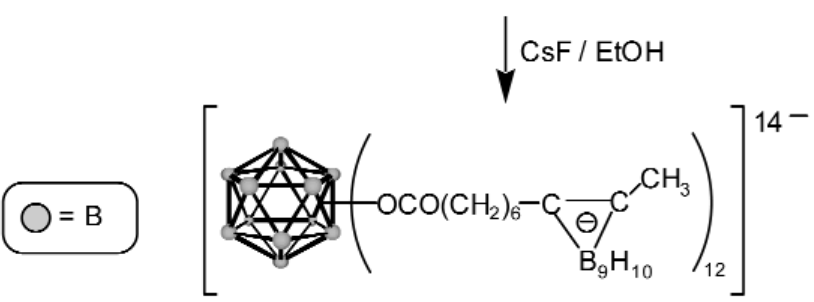

11

Scheme 5 Closomer derivative of high boron content for possible use in boron neutron capture therapy.

10, shown in Fig. 6, reveals the presence of 132 boron atoms, its spherical shape, and approximately $3.5 \mathrm{~nm}$ diameter. Water-soluble $\mathbf{1 1}$ (as Na salt) will be evaluated for boron neutron capture therapy applications in the near future.

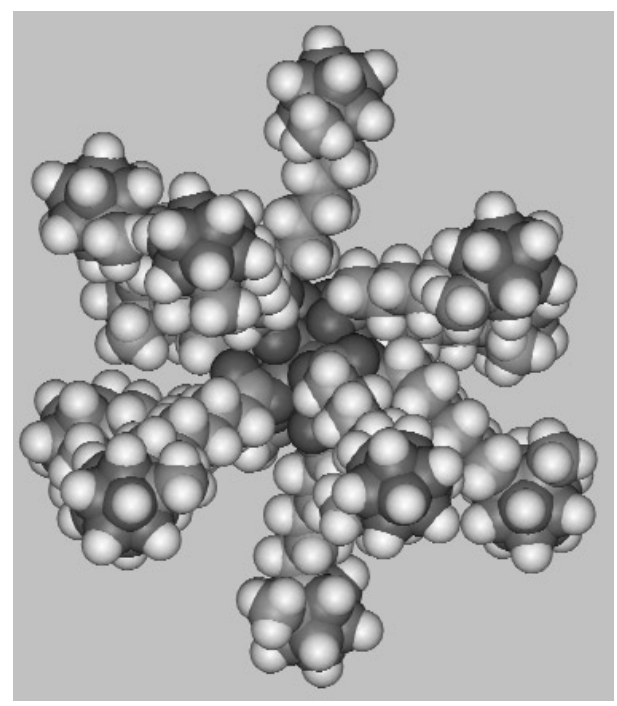

Fig. 6 Space-filling structure of $\mathbf{1 0}$ (Scheme 5).

\section{Water-soluble carborane scaffold for closomer chemistry}

The ready availability of $\mathbf{3}$ prompted [10] its use as the core of a carborane-based, water-soluble closomer system described in Scheme 6. The bis-sulfinic acid $\mathbf{1 2}$ is readily oxidized to the water-soluble decahydroxy bis-sulfonic acid 13. Methylation of $\mathbf{1 3}$ afforded the species 14. These are the first reported reactions using a totally B-hydroxylated carborane closomer derivative. 


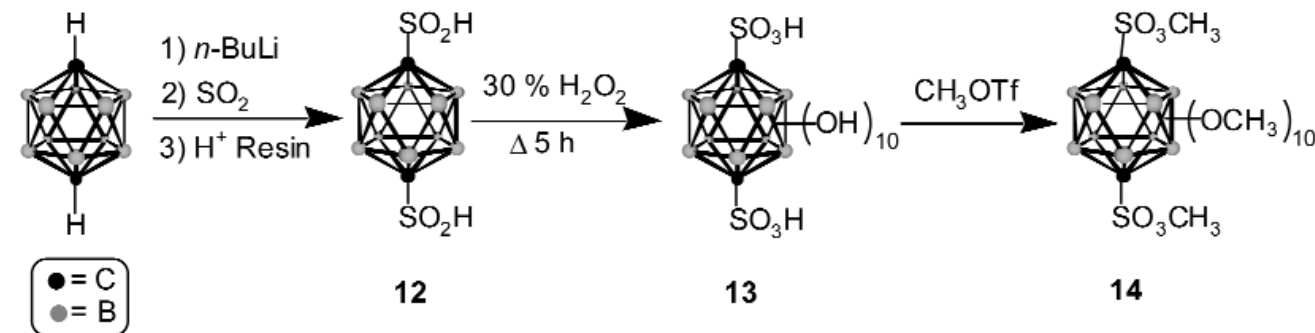

Scheme 6 Water-soluble carborane scaffold for closomer chemistry.

\section{CONCLUSIONS}

The discovery of closomers opens an exciting new chapter in polyhedral borane chemistry since they are easily envisioned in many roles involving biomedicine, materials science, and nanotechnology. Adaptations of closomer structures derived from $\mathbf{1}$ are currently under investigation, and the results will be reported elsewhere. Further advances at the interface of boron and carbon chemistries are apparent and demand broad exploitation.

\section{ACKNOWLEDGMENTS}

The author is grateful for support of this research by the U.S. Department of Energy Grant Number DE-FG03-95ER61975 and the National Science Foundation Grant Number CHE-0111718. He also thanks his coworkers at UCLA for their many contributions which made this research possible.

\section{REFERENCES}

1. H. C. Brown. Organic Syntheses Via Boranes. Wiley, New York (1975).

2. M. F. Hawthorne. In Advances in Boron Chemistry, W. Siebert (Ed.), p. 261, Royal Society of Chemistry, Cambridge (1996).

3. M. F. Hawthorne. In Contemporary Boron Chemistry, M. G. Davidson, A. K. Hughes, T. B. Marder, K. Wade (Eds.), p. 197, Royal Society of Chemistry, Cambridge (1999).

4. T. Peymann, A. Herzog, C. B. Knobler, M. F. Hawthorne. Angew. Chem., Int. Ed. 38, 1061 (2001).

5. T. Peymann, C. B. Knobler, S. I. Khan, M. F. Hawthorne. J. Am. Chem. Soc. 123, 2182 (2001).

6. A. Maderna, C. B. Knobler, M. F. Hawthorne. Angew. Chem. 40, 1662 (2001).

7. T. Peymann, C. B. Knobler, S. I. Khan, M. F. Hawthorne. Angew. Chem. 40, 1664 (2001).

8. L. M. McKee. Inorg. Chem. 41, 1299 (2002).

9. J. Thomas and M. F. Hawthorne. Chem. Comm. 1884 (2001).

10. A. Herzog, C. B. Knobler, M. F. Hawthorne. J. Am. Chem. Soc. 123, 12791 (2001).

11. M. F. Hawthorne and K. Shelly. J. Neuro-Oncology 35, 2963 (1977). 